First Peoples Child \& Family Review

A Journal on Innovation and Best Practices in Aboriginal Child Welfare Administration,

Research, Policy \& Practice

\title{
A Commentary Against Aboriginal to non-Aboriginal Adoption
}

\section{Kenn Richard}

Volume 1, numéro 1, 2004

URI : https://id.erudit.org/iderudit/1069588ar

DOI : https://doi.org/10.7202/1069588ar

Aller au sommaire du numéro

Éditeur(s)

First Nations Child and Family Caring Society of Canada

ISSN

1708-489X (imprimé)

2293-6610 (numérique)

Découvrir la revue

Citer ce document

Richard, K. (2004). A Commentary Against Aboriginal to non-Aboriginal Adoption. First Peoples Child \& Family Review, 1(1), 101-109.

https://doi.org/10.7202/1069588ar

\section{Résumé de l'article}

This article focuses on the author's experience and observations respecting the appropriateness of adopting Aboriginal children into non-Aboriginal settings, and its impact on children, youth and parents receiving services from an Aboriginal child and family services agency in Toronto. 


\section{Abstract}

This article focuses on the author's experience and observations respecting the appropriateness of adopting Aboriginal children into non-Aboriginal settings, and its impact on children, youth and parents receiving services from an Aboriginal child and family services agency in Toronto.

\section{A Commentary Against Aboriginal to non-Aboriginal Adoption}

\section{Kenn Richard}

\section{Introduction}

The issue of the appropriateness of adoption of Aboriginal children by nonAboriginal people is one that has been hotly debated for many years. Despite court battles on individual cases, human rights tribunals related to class action from both sides, and many newspaper and related media attention to the issue, there exists no consensus on what is in the best interests of Aboriginal children in need of long term care.

This commentary presents an argument against the adoption of Aboriginal children by non-Aboriginal families. The arguments as presented are from a cultural perspective, not the political, and thus also does not flow so much from hard research as much as it does from practical experience. The major thrust of my argument is based primarily on the cultural issues at play as I have observed in my experience as the executive director of an urban Aboriginal service agency.

Aboriginal children are presented within their cultural context with their best interests tied to cultural considerations. These in turn attach to the difficulties of Aboriginal children in non-Aboriginal care in managing critical milestones such as identity formation during adolescence. It is observed that many Aboriginal to non-Aboriginal adoptions break down at that time and it's concluded that the interplay of cultural dynamics and identity formation play a significant role in this process. Bonding, continuity of care, cultural maintenance of Aboriginal children in non-Aboriginal care is also discussed within the cultural domain. These principles are referenced repeatedly in the journalistic and academic discourse yet they are of questionable value given their bias in favor of Anglo European world views.

I am informed primarily by my experience in child welfare, an experience which dates back to 1973. I am further informed through my work at the University of Toronto where I have taught Cross Cultural Social Work Practice for a number of years. Finally, and perhaps most importantly, I am informed by the "stories" I have heard over the past years, 
The "best interests of the child" principle has evolved over time, through policy, social work practice and the courts, to become the primary consideration in planning for a child. While the principle seems self evident and culturally neutral it is defined subjectively through a value, knowledge and practice context that is decidedly Anglo European. The notion of the child and her best interests, as separate and distinct from her family, community and culture, is one that has its roots in the individualist orientation of European culture. stories that are not always written down but nevertheless are compelling arguments in support of intra-cultural placements of Aboriginal children.

\section{The Broader Context}

With revisions to the Indian Act in 1951 and the implementation of the Canada Assistance Plan in 1966, came significant changes regarding the delivery of Child Welfare services to Aboriginal and First Nation communities. Prior to 1951 few resources were dedicated to delivering services on reserves and staff from off reserve Child Welfare authorities were generally directed to enter reserve communities in their official capacity only if it was a matter of "life or death."

With the above changes came the need to settle issues of jurisdiction and responsibility. Provinces were granted authority on reserve and federal cost sharing to offset Provincial costs was instituted. As a result provincial Child Welfare authorities became more active within First Nations communities and children began to be apprehended at rates dramatically disproportionate to the size of the First Nations child population. By the end of the sixties, according to research cited by Fournier and Crey (1997), up to $40 \%$ of all children in care were status Indian children despite the fact that these children represented less than $4 \%$ of the population.

With the apprehension of Aboriginal children comes the issue of state directed care arrangements. Most children were not placed with Aboriginal families and they were least likely to be returned to their families in their home communities. Aboriginal children are also least likely to be adopted and most likely to have multiple foster care placements until the state relinquished its responsibility at the child's age of majority (Fournier and Crey, 1997).

With regard to adoption the total number of First Nations children adopted by non-Aboriginal families increased five fold from the early 60 's to the late 70 `s. From 1969 to $1979,78 \%$ of all First Nations children who were adopted were adopted by non-Aboriginal families (Fournier and Crey, 1997: 3).

\section{The Best Interests of the Child}

The "best interests of the child" principle has evolved over time, through policy, social work practice and the courts, to become the primary consideration in planning for a child. While the principle seems self evident and culturally neutral it is defined subjectively through a value, knowledge and practice context that is decidedly Anglo European. The notion of the child and her best interests, as separate and distinct from her family, community and culture, is one that has its roots in the individualist orientation of European culture. Here the child is seen as a discrete unit and her relationships are measured in accordance with the degree to which they are harmful or helpful to her well-being and welfare.

This view stands in contrast to the world views of tribal societies, including First Nations in Canada. Within the tribal world view, individuals, while acknowledged and valued, are contextualized within families, communities and cultures. Here the best interests of a child are inexorably linked to the best interests of the community and vice versa. As the child is seen as the embodiment of her culture she is as a result required to be nurtured within it. Given this symbiotic relationship the community is thereby compelled to do its best in producing well adjusted and productive adults to further strengthen the collective through the generations. This is not only good for the child but necessary for the overall survival of the community of which she is an integral part. The notion of rights of any one party is subservient to the notion of responsibility to care for children. The children, because cultural and community survival depend on them, 


While Aboriginal child
welfare is still in the early
stages of development,
many believe that
Aboriginal children are
now better off in the newer
developing Aboriginal
controlled systems than in
the mainstream context.

While Aboriginal child welfare is still in the early stages of development, many believe that now better off in the newer developing Aboriginal the mainstream context. are considered sacred. The idea of the child being considered apart from her context simply cannot be easily fathomed by collectivists (Fournier and Crey, 1997).

For the child, the collective approach not only nurtures but also provides a clear identity and a sense of belonging. This is a critical indicator of successful adjustment in adult life. Anglo European ideology, on the other hand, may consider culture and community as a factor but its fundamental linkages to the child's best interests are often superseded by considerations more compatible with their world views. Here "objective" reality prevails although that reality is colored significantly by the culture through which it is interpreted. Child developmental psychology, as written primarily by those with an individualist orientation and tested with non-Aboriginal children, is given credence over non-scientific beliefs about a child's best interests and beliefs based on practical experience over time and through multiple generations within the tribal context.

While both tribal societies and Anglo European cultures would be concerned with the best interests of the child, the defining of best interests and the consideration of factors related to it are culture bound. Given that the Canadian child welfare system, its legislations, standards, practices and processes, were crafted by Anglo European settlers it is not surprising that the cultural context of the Aboriginal child bears little weight. What is given the greatest weight is that which conforms to the dominant paradigm. Thus " bonding" and "continuity of care" are often cited by the courts as key considerations in decisions as to the child's best interests as they attend to what is considered important from the individualist's orientation. While bonding and continuity of care are also considered important within the tribal perspective, it is balanced by other considerations related to the cultural context of the child and her best interests within it.
The dichotomy identified here is not merely academic argument; it has had profound effects on judgments related to the best interest of Aboriginal children. By emphasizing one world view and marginalizing another, the child welfare system has historically missed or discounted critical components in the assessment of Aboriginal children. Aboriginal specific provisions in legislation, among other measures, serve to shift the mind set of the practitioner towards a more inclusive and holistic framework for the assessment to the best interests of the Aboriginal child. We are informed by practice that culture is important, and legislation now enables it to take its place in the totality of considerations in best interest considerations.

While studies need to be done, practical experience within the Aboriginal sector indicates that, in the adoption arena, the Aboriginal child is one child where the presence of culture is a strong indicator of adoptive success. With the arrival of Aboriginal child welfare authorities and the resultant paradigm shift fewer Aboriginal children are being removed from communities and more are benefiting from stable community placements. A report from the Federal Department of Indian Affairs indicates a progressive drop in the number of placements from $6.5 \%$ in the mid seventies to just $3.6 \%$ in $1995 / 96$ (DIAND, 1997:5).

Among many professionals, Aboriginal and non-Aboriginal alike, there is emerging consensus that the shift toward the control of Aboriginal child welfare to Aboriginal communities holds more promise than the status quo as exemplified by historical mainstream child welfare practices. While Aboriginal child welfare is still in the early stages of development, many believe that Aboriginal children are now better off in the newer developing Aboriginal controlled systems than in the mainstream context. 
Often, the adopted child, whether Aboriginal or not, must deal with what may be viewed as a chronic doubt as to their individual worth. No matter how sensitive adoptive parents may be to the issue, the child often questions why her own family of origin let her go.

\section{Bonding and its Relationship to Future Success}

Anglo European frames of reference, when applied to Aboriginal children, often fail in their efforts at predicting successful outcomes. Bonding, that tie between an individual care giver and her child that implies an in depth and deeply attached emotional relationship, has increasingly been a primary consideration guiding both practitioners and the courts in their efforts to make appropriate decisions in the best interests of a child. This, not surprisingly, is also more consistent with the individualistic ideology of Anglo European culture. It is also reinforced by a generic knowledge base informed almost exclusively through the study of non Aboriginal children and families.

While on the surface this consideration seems valid and appropriate, the fact remains that an Aboriginal child bonded to her non Aboriginal care giver is not (and many cases will attest to this) necessarily going to maintain the bonded relationship over time. Often the well bonded four year old becomes the raging adolescent bent on both personal and familial self destruction. While bonding is believed by many to be an accurate predictor of adoption success, no studies carried out with Aboriginal children in adoptive homes can be referenced to substantiate this belief. Again practical experience in the field leads me to conclude that bonding as an accurate predictor of success in adoptions is clearly challenged by reality, at least in reference to the experience of Aboriginal children.

The Aboriginal adolescent adopted into a non-Aboriginal family is a child that has almost insurmountable challenges facing her in her path toward adulthood. She must not only deal with the problems associated with adolescence, she must attend to the fact that she is adopted and the reality that she is an Aboriginal child in a non-Aboriginal world.

Child development, as articulated by western theorists, is predicated on the successful completion of various life stages all leading to the creation of an emotionally intact and functioning adult. One of the most challenging stages occurs in adolescence when a child must resolve all issues related to identity formation. In this stage a child is compelled to "individuate" or, put more simply, to develop a sense of self separate and apart from her parents. Self esteem, the ability to trust, a sense of where one is placed in the broader scheme of things, a history that can guide and inform; all these are import components of the process toward adulthood.

While the goal is to separate oneself from parents the process is informed by the parents themselves, the environment in which they live and what the child sees in the mirror. If the information appears contradictory or confusing, or is experienced in a negative way by the child, then problems may well emerge having serious consequences for both the child and her parents.

Often, the adopted child, whether Aboriginal or not, must deal with what may be viewed as a chronic doubt as to their individual worth. No matter how sensitive adoptive parents may be to the issue, the child often questions why her own family of origin let her go. She may feel she did something wrong or that she was not wanted in the first place. Each child will have doubts based on their own interpretation of the facts but many conclude that they were at least partially at fault. Being at fault implies a huge challenge to the child's self esteem, a challenge many do not deal with adequately. Add feelings of abandonment felt by many and it's a bigger challenge than many can handle.

The Aboriginal adoptee in a nonAboriginal family is further challenged by their Aboriginal status. They have little information as to what this really means and rely on messages from their parents and the broader environment in which she lives. Subtle and not so subtle messages 
The world is very diverse in its ways of organizing systems of child care. No one culture is recognized to be better than the next in producing well adjusted, happy and productive adults. will often tell her that she is lucky to be out of her birth culture and that the Aboriginal community is not capable in providing good care for children. She rarely sees the diversity of Aboriginal life and absorbs the stereotyping, often negatively, that abounds in North American society.

Dr. Leo Steiner, former director of the Aboriginal Community Crisis Team at the Toronto East General Hospital, in an affidavit to the Family Court in Toronto in 1990, said the following in a case regarding cross cultural Aboriginal adoption:

A child who is conflicted about his identity is severely handicapped. He may have developed a host of functional skills, but he is also subject to a gnawing, chronic self questioning. The child becomes a victim of a self fulfilling prophecy, self sabotaging his own attempts at success for he strongly believes he is doomed to failure. With low self esteem and a confused sense of self, the child is ill equipped to form healthy and mature relationships with others. He is then more likely to seek short term pleasures rather than more productive realistic long term goals. Unable to interact meaningfully in adulthood, he often develops a self centered, impulse pleasing self destructive life style.

\section{Continuity of Care from the Aboriginal Perspective}

The primary assumption underlying this principle is that every child needs consistency regarding his or her care arrangements. In many ways this principle serves as a vehicle that will promote the positive bond that is seen as critical in healthy child development. When consideration is given this principle the focus of analysis is on individual nuclear families usually with one set of parents. Grand parents and other related care givers are sometimes factored into the assessment but only if they have taken an active role in parenting the child. This principle, like that of the best interests of the child, has been defined and elaborated almost exclusively within the Anglo European cultural context. As with the practical interpretation of the best interest principle continuity of care is interpreted only in a manner consistent with those holding an individualist world view.

The traditional Aboriginal family is no family at all by Anglo European standards. Aboriginal families are in fact a child centered and caring community of people, some related by blood, some tied by clan or other indigenous social structures, who all have responsibility for the good and welfare of the community's children. As such a child may be cared for by her natural mother, an aunty, and a cousin at different points in the child's life. This is not a problem within traditional Aboriginal culture. In fact this has traditionally been seen as desirable in order to produce a child who embodies the totality of tribal experience, its values, knowledge and ways of behaving.

Thus what may have been misunderstood and judged by nonAboriginals as "inconsistent parenting" or a "disorganized family life" is culture taking its course in an Aboriginal context and not the expression of problems. Judgments from one cultural context over another will always be flawed as they are not informed by the culture of the other. Non-Aboriginal systems use standards rooted in world views that are essentially foreign and judges miss important considerations as a result. The world is very diverse in its ways of organizing systems of child care. No one culture is recognized to be better than the next in producing well adjusted, happy and productive adults. To think otherwise would expose the colonial mind set since judged to be racist in its underpinnings and historically damaging to Aboriginal people in this country. 
Native Child and Family

Services of Toronto, founded in 1985, provides child welfare related services to an estimated 40,000 Aboriginal people in the Greater Toronto area. It has a full range of prevention programs, provides treatment and healing services, and is a licensed foster care provider. It manages a large Aboriginal child welfare caseload and has an extensive program for youth on the street. In July 2004 the agency will become the fourth Children's Aid Society in Toronto and as a result becomes the first fully operational off reserve Aboriginal child welfare authority in Canada.

\section{Aboriginal Cultural Maintenance in the Non-Aboriginal Context}

Adoptive parents of Aboriginal children inevitably agree to make efforts towards nurturing the child's cultural self as an Aboriginal person. While well intended this is almost impossible to achieve and may in fact exacerbate the problems of identity. Culture is complex but its transmission is simple. Put a child within a certain cultural milieu and an organic process of acculturation occurs. It is through everyday living that the values, beliefs and culturally prescribed behaviors are learned. This immersion in culture is the vehicle of acculturation. The agents of it are primary relationships in the child's life, parents, relatives, educators and the like. If an Aboriginal child is being raised in a non-Aboriginal environment they will acculturate within its cultural context. I have met full blooded Aboriginal children who were culturally Dutch, British and Swiss.

Exposing an Aboriginal child who has been brought up outside her birth culture to Aboriginal life can exacerbate identity formation problems further. If the child has identity confusion or is otherwise conflicted then exposure to Aboriginal culture may trigger chronic anxiety and all its consequences. She is reminded of her estranged status and is told, sometimes subtly, sometimes not, that she is not really an Aboriginal person. If she also feels that she is not legitimately part of her adoptive family's cultural heritage, which many do, then she is in real danger of being stuck with an insurmountable task regarding her identity formation. She is not as a result comfortable in her relationships and feels alienated and is alienated from those who care about her. While Aboriginal children may be exposed to their cultural heritage this exposure may only amount to enhanced cultural literacy. These children may know only a few words of the language, have developed skills in certain crafts, but fundamentally they are estranged from their heritage and may be viewed as tourists in their Aboriginal land. As one father put it whose sons returned to their home reserve after years in adoptive care:

It was not easy ... they showed no respect for their mother, they expected to be looked after, they expected their meals on time, they swore in front of the girls, they talked "man" this and "man" that ... They couldn't fit into our life. They are strangers ... (To Serve and Provide: A Case Study in Planning Indian Community Services for Children and their Families, $p$. 17, cited in Native Child and Family Services of Toronto, Stevenato and Associates and Budgell, p. 66).

\section{Experience at Native Child and Family Services of Toronto}

Toronto has experienced first hand the legacy of best interest of child decisions made some 20 years ago simply because it is situated in the centre of a large population into which many Aboriginal children were adopted. While numbers are elusive, many Aboriginal children from all over Canada were adopted to nonAboriginal families in southern Ontario. Native Child and Family Services of Toronto, founded in 1985, provides child welfare related services to an estimated 40,000 Aboriginal people in the Greater Toronto area. It has a full range of prevention programs, provides treatment and healing services, and is a licensed foster care provider. It manages a large Aboriginal child welfare caseload and has an extensive program for youth on the street. In July 2004 the agency will become the fourth Children's Aid Society in Toronto and as a result becomes the first fully operational off reserve Aboriginal child welfare authority in Canada.

Of significance is the number of people served by Native Child and Family Services who have experienced adoptive breakdowns. Adoptive breakdowns are simply those adoptions where the child leaves the home prior to their reaching the 


A profile of the typical
Aboriginal youth on the
street in Toronto is that
of a young male, often a
runaway from an adoption
home, who has been on
the street since he was
14 years of age. ... He
likely carries considerable
unhealed trauma related
to physical and/or sexual
abuse and has probably
contemplated and perhaps
attempted suicide at least
once. He is not likely to
avail himself of services
unless he has no choice
and he is one who rarely
follows through on any
formulated case plans.

A profile of the typical Aboriginal youth on the street in Toronto is that of a young male, often a runaway from an adoption the street since he was 14 years of age. ... He likely carries considerable unhealed trauma related to physical and/or sexual abuse and has probably contemplated and perhaps once. He is not likely to avail himself of services unless he has no choice and he is one who rarely formulated case plans. age of majority. We have found that with regard to the women assisted through our child welfare related services, treatment and healing programs, the majority have not been raised by their natural extended families in their home communities. The majority of these women were either raised by the government in both foster care and/or institutions or they were adopted at an early age and sent far from their home territories. Within this population at least half have been adopted.

Within the adopted population, many have experienced a breakdown in their placement resulting with them leaving their adoptive placements prior to reaching the age of majority. Native Child and Family Services of Toronto provides child welfare, treatment and healing services to approximately 300 women of this population at any point in time. It is estimated that almost 200 of these women will have been raised in places other than their own home or community. Of these 100 women, at least half have experienced breakdowns in their placement.

What happens to these women? Typically, they do not return to their home communities nor do they establish relationships with their natural families. Some become chronic runaways or are drawn to the streets of large urban cities such Toronto. Many finish their adolescence in a series of placements provided by the child welfare system and are simply discharged with little or no follow up on reaching the age of majority, sixteen years as defined by the Child and Family Services Act in Ontario. All are alienated from both their adoptive family and from their home communities. Many carry significant unhealed trauma that contributes to higher addiction rates and a tendency to enter and stay in abusive relationships. Many of these women get pregnant young and quickly slide into a life of isolation, loneliness and despair. Almost all of these women live in poverty and many will lose their own children to the child welfare system. The irony here is that somewhere, when these mothers were children, a well intentioned social worker made a decision in the child's best interests that, in reality and over time, led to the a replication of the very circumstances that led to their own apprehensions. This time it's their own children and the cycle repeats itself into yet another generation.

The situation is even bleaker for Aboriginal youth on the street. According to a study done by the Addiction Research Foundation in the early 1990s, Aboriginal youth represent $20 \%$ of all youth chronically on the streets of Toronto. This number is high considering that Aboriginal youth represent less than $2 \%$ of the total Toronto youth population. A profile of the typical Aboriginal youth on the street in Toronto is that of a young male, often a runaway from an adoption home, who has been on the street since he was 14 years of age. He will likely have some involvement with the criminal justice system and will often be cross addicted to both alcohol and street drugs. He likely carries considerable unhealed trauma related to physical and/or sexual abuse and has probably contemplated and perhaps attempted suicide at least once. He is not likely to avail himself of services unless he has no choice and he is one who rarely follows through on any formulated case plans. He is either a loner or is part of group of other Aboriginal youth in similar circumstance and from similar backgrounds. He has little hope and knows that his fate is likely to be jail or, as is sometimes is the case, a violent death on the street.

In our experience these youth, without assistance, will follow a predictable pattern. Being on the street at an early age, they become, over time, the hard core and hardest to serve of all youth on the street. They do not utilize conventional services available and are to a large degree alienated even from conventional street culture. These youth are highly visible when in an intoxicated state, as they often are, yet at the same time make themselves almost invisible when sober. They tend to 


Too many of our youth
have died since we
began our youth focused
programs. With the
advent of devolving
mandates to Aboriginal
authorities it is imperative
that the full scope of
child welfare related
problems associated
with Aboriginal children
is adequately researched
and documented. The
new Aboriginal authorities
not only need good
research on the nature
of the problems but also
articulation on promising
solutions that are informed
by culturally competent
forms of best practice
models of service that do
and/or may exist elsewhere
in Canada.

Too many of our youth

cied since we

programs. With the

advent of devolving mandates to Aboriginal authorities it is imperative that the full scope of child welfare related problems associated with Aboriginal children and documented. The new Aboriginal authorities not only need good research on the nature of the problems but also articulation on promising solutions that are informed by culturally competent forms of best practice and/or may exist elsewhere in Canada. exist in this state for years until they either die violently of lifestyle related causes, graduate to being adult street people, or are incarcerated, often for petty crimes that are repetitive and thus dealt harshly by the courts.

Too many of our youth have died since we began our youth focused programs. Some of the youth involved in our programs have died of AIDS; four died violently on the street and there have been suicides. One youth died in Ottawa after being beaten and dowsed with cooking sherry and set on fire by two other Aboriginal street youth. This youth experienced an adoption breakdown. He had done well in our program but moved to Ottawa to start anew. Without supports such as that provided by Native Child and Family Services of Toronto, he went back to the street and died.

Another young man, again an adopted child, lived an uneventful life in his adoptive placement until he reached twelve years of age. As a child he and his brother were removed from his family in northern Ontario and adopted by a school principal and his wife in a small southern Ontario community. Upon reaching adolescence he and his brother began acting out. They both began skipping school and getting involved in petty theft. While the family, who by all accounts were loving and caring to these children, tried to understand what had happened to these boys. The boys' behavior escalated to the point where they began running away for days at a time. The two boys often went to Niagara Falls or Toronto where they were drawn into life on the streets. Alcohol, drugs and violence became the prominent themes in their everyday lives. In due course, the older brother killed himself by leaping into the Niagara River just below the famous falls. The young brother eventually left his adoptive home soon after, and made his way to Toronto where he became involved in Native Child and Family Services of Toronto youth program. While he appeared to be making progress, he died in suspicious circumstance on the street one year ago. His family as well as our program staff still mourn his loss.

Native Child and Family Services of Toronto have a photograph of four young men, all smiles and good looks at our summer residential camp. All four had been adopted into non Aboriginal homes as young children. Of the four, three are dead and one is still on the streets, addicted to both heroine and alcohol.

\section{Conclusion}

Aboriginal provisions in child welfare legislation, those that recognize the significance and importance of Aboriginal culture within the best interest of child consideration provide some optimism. Based on emerging knowledge and considerable practice experience, the evidence, clinical and otherwise, however tells me that equal weight must be given to the cultural context of the child as has been given to culturally biased interpretations of bonding or continuity of care. Remarkably there is a lack of research associated with the issues to which I have outlined in this commentary. With the advent of devolving mandates to Aboriginal authorities it is imperative that the full scope of child welfare related problems associated with Aboriginal children is adequately researched and documented. The new Aboriginal authorities not only need good research on the nature of the problems but also articulation on promising solutions that are informed by culturally competent forms of best practice models of service that do and/or may exist elsewhere in Canada.

Currently significant funds are being spent in court battles where the lives of vulnerable Aboriginal children are being decided based on incomplete, biased, and subjective information touted as hard science. A fraction of the dollars spent on lengthy litigation, if routed toward quality research, could serve to get the field beyond the rhetoric and emotionalism that further characterizes the current discourse 
on the issue of cross-cultural adoption. Finding consensus is the challenge to all stakeholders and one that deserves to be addressed not for the sake of argument but for the sake of the children affected.

\section{References}

Fournier, S. and Crey, E. 1997. Stolen from Our Embrace: The Abduction of First Nations Children and the Restoration of Aboriginal Communities.

Vancouver, Douglas and McIntyre.

Tiechroeb, R, . 1997. Flowers on My Grave: How an Ojibway Boy's Death Helped Break the Silence on Child Abuse. Toronto: Harper Collins Publishers Ltd.

Kline, M Child Welfare Law, "Best Interests of the Child" Ideology, and First Nations." In Osgoode Hall Law Journal, 30 (2): pp. 375-425.

Hall, Edward T. 1981. Beyond Culture. Doubleday.

Department of Indian Affairs and Northern Development (DIAND). 1997.

Basic Departmental Data 1996. Departmental Statistics Section, Information Quality and Research Directorate, Information Management Branch. Ottawa, ON. Available from http://www.ainc-inac.gc.ca/pr/sts/ bdd96/Bdd96 e.pdf.

Native Child and Family Services of Toronto, Stevenator and Associates and Janet Budgell. 1999. Aboriginal Healing and Wellness Strategy. Research Project: Repatriation of Aboriginal Families - Issues, Models and a Workplan. Authors. Retrieved from http://www.nativechild.org/rep rpt.pdf. 